\title{
Sustainable tourism in an urban desert
}

\author{
R. Cameron, S. Conway \& P. Washeba \\ Urban Environmental Research, LLC, USA
}

\begin{abstract}
In the United States and in a number of other countries around the world, LEED certification has become the recognized standard for measuring building sustainability. Achieving LEED certification is the best way to demonstrate that your building project is truly "green". MGM Resorts International recognized that sustainable development of its CityCenter project was vitally important to making sure that the Las Vegas Valley will continue to have, the water, materials, and resources to protect human health and our environment, while providing an aesthetically pleasing environment to its residents and customers

Keywords: sustainable development, green building, LEED, sustainable tourism, Las Vegas, economic impact.
\end{abstract}

\section{Introduction}

The Las Vegas Strip has always been known for its bright neon lights and stunning array of bold colors, but increasingly the "Strip" has taken a leadership role in promoting environmental sustainability. Environmental sustainability is the concept of conserving scarce resources today to protect the future. This paper focuses on the efforts of MGM Resorts International to build an urban resort destination that was created with a vision to bring a new level of environmental consciousness to the world-famous "Strip". To realize this plan, MGM Resorts International executives met with numerous architects to review their work and understand their approach to environmental sustainability. When the search was concluded, MGM Resorts International chose eight of the world's foremost architects to begin the design phase that would take CityCenter from concept to reality. The eight-architects engineered a "city within a city", where residents and visitors alike can live, work, and play in its 67-acre footprint. This unique community is transforming expectations, and is providing a remarkable 
demonstration that a community can be both beautiful and sustainable not only for today, but for future generations as well.

\section{Commitment to sustainability}

MGM Resorts International has set a standard for LEED Certification in Las Vegas and the State of Nevada. This paper focuses on MGM Resort International's commitment to sustainability [1] in the following ways:

- Impact on Energy Usage;

- Water;

- Wellness;

- Recycling;

- Materials;

- Transportation; and

- Transformation.

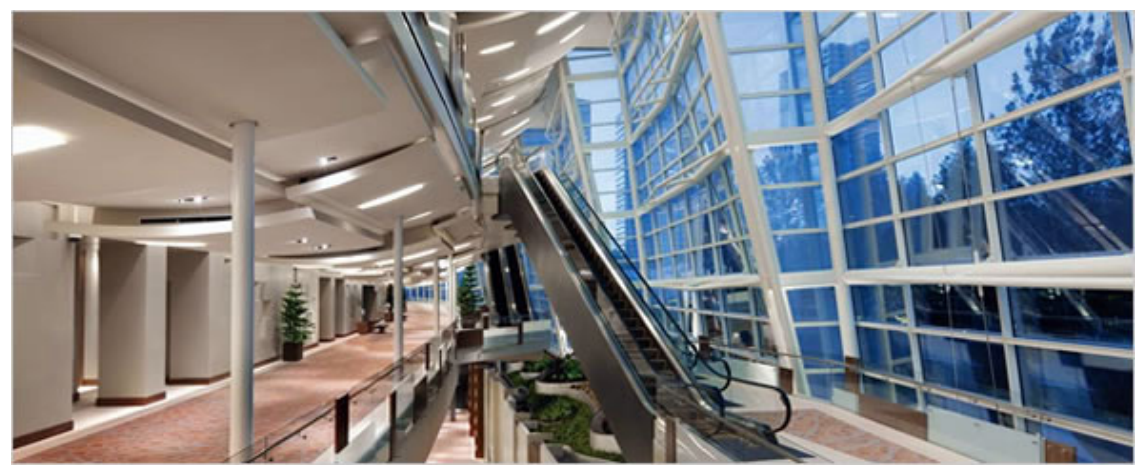

Figure 1: $\quad$ Aria Hotel and Casino.

From its inception to design, and from development to construction, the goal was to create a destination that is environmentally sustainable, but also operates with an equal commitment to conserving natural resources.

CityCenter set a standard for responsible sustainable growth in Las Vegas when it pursued the U.S. Green Building Council's Leadership in Energy and Environmental Design $\left(\right.$ LEED $\left.^{\circledR}\right)$ certification. LEED is the nationally accepted benchmark for design, construction and operations of high-performance green buildings. More than 60 LEED-Accredited Professionals contributed their expertise to CityCenter over the project's five-year design and construction process. CityCenter is the world's largest environmentally sustainable, mixeduse new construction development to achieve LEED certification. The State of Nevada currently has sixty-eight LEED Certifications; forty-eight of them in Clark County another fifteen in Nevada's second largest Metropolitan area, Washoe County (see Table 1). 
Of the forty-eight LEED certified sites, CityCenter comprises six of those sites including; Aria Resort \& Casino's hotel tower, convention center and showroom; as well as Vdara Hotel and Spa, Mandarin Oriental, Crystals, and Veer Towers have all received USGBC's LEED Gold certifications.

Table 1: $\quad$ Number of LEED certified buildings in Nevada.

\begin{tabular}{ll}
\hline County & Total \\
\hline Clark & 48 \\
Other & 5 \\
Washoe & 15 \\
Total Nevada & 68 \\
\hline
\end{tabular}

Of the sixty-eight LEED Certificates issued to facilities in the State of Nevada, thirty-two have been certified as Gold, to include the six CityCenter properties (see Table 2).

Table 2: $\quad$ Certificate types of LEED certified buildings in Nevada.

\begin{tabular}{ll}
\hline Certificate Type & Total \\
\hline Platinum & 4 \\
Gold & 32 \\
Silver & 23 \\
Certified & 9 \\
Total Nevada & 68 \\
\hline
\end{tabular}

The CityCenter team also set the standard for responsible resort operations. CityCenter uses energy efficient appliances in its residential units and lowwattage lights in the parking garages. CityCenter also uses non-toxic cleaning supplies throughout the property. CityCenter represents a new, more responsible approach to the value proposition of the industry, offering sustainable solutions for visitors and residents alike.

\section{Impact on energy usage}

Measures taken during the design process to reduce the amount of fossil fuelbased power used at CityCenter resulted in a 30-percent increase in energy efficiency, as compared with similar buildings using traditional building design. The amount of energy saved by the efficient design of CityCenter is equal to the average annual power use of 8,800 homes [2].

CityCenter generates its own electricity on site. A $\$ 100$ million $9 \mathrm{MW}$ $(12,000 \mathrm{hp})$ state-of-the-art central power plant designed by Siemens uses natural gas to create electricity, then captures emitted heat before it enters the atmosphere to meet the domestic hot water needs of all buildings and swimming 


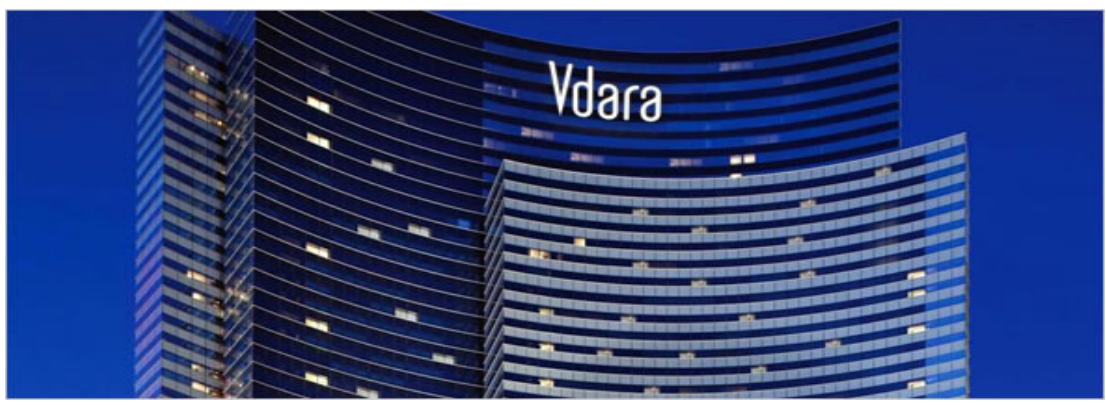

Figure 2: $\quad$ Vdara.

pools in the complex. This highly efficient cogeneration plant significantly reduces the energy that would otherwise be required by boilers to heat water.

CityCenter also uses low-wattage lighting that sets the ambiance in guest rooms, public spaces, and garages. CityCenter utilizes cutting-edge illumination technologies such as compact fluorescent light bulbs, light-emitting diodes (LEDs), and cold cathode light systems.

Sophisticated ENERGY STAR appliances such as clothes washers, dishwashers, and refrigerators have been installed in every condominium unit. Window glazing, building shades, and light-colored rooftops reflect and deflect intense desert sunlight before it can enter buildings at CityCenter. This dramatically reduces the amount of energy required to cool indoor spaces.

Electronic monitoring by computerized control systems, combined with periodic building inspections help to ensure that all systems are performing at their optimum capacity while maximizing energy conservation throughout the property.

\section{Water}

The City of Las Vegas resides in the Mojave Desert where water is a precious resource CityCenter uses advanced plumbing designs, and continues to invest in low-flow technologies [3]. Conscientious operating practices is a priority at CityCenter and the development team incorporated water conservation programs throughout the entire resort. As a result, CityCenter saves nearly 50 million gallons of water each year, which is the amount of water used annually by 380 Las Vegas homes.

During construction of CityCenter, water reclaimed from the adjacent Monte Carlo Resort's cooling tower was used to control dust, saving 2.4 million gallons of potable water and the energy required to process and pump it.

Low-flow fixtures such as showerheads, faucets, and toilets were selected by designers for both their aesthetic appeal and functionality. Without compromising performance, these fixtures deliver water savings of more than 30 percent as compared to standard bathroom fixtures. 


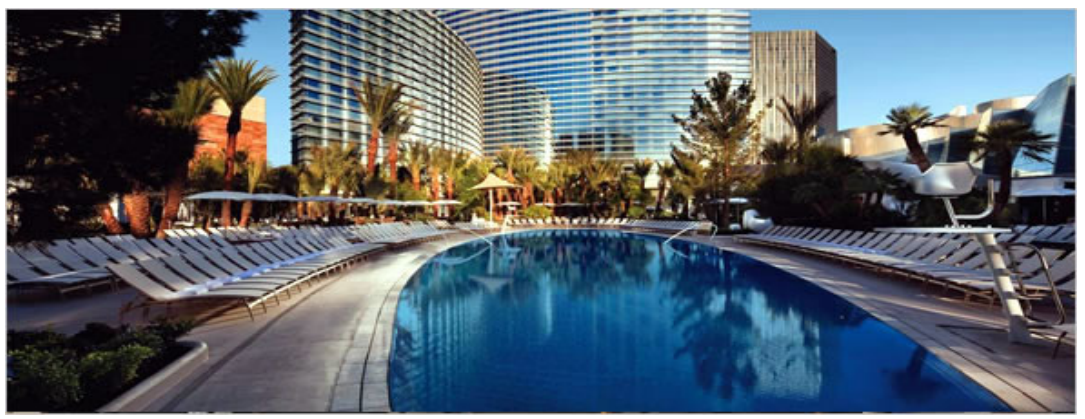

Figure 3: $\quad$ Pool at CityCenter.

Given the fact that CityCenter is located in the Mojave Desert, native and drought-tolerant plant species are utilized in landscaping for their heat and lowwater tolerance.

Exterior vegetation which uses 60 percent less water than traditional landscape designs are monitored by moisture-control sensors and other technologies to ensure that the landscaping is irrigated only as needed.

\section{Wellness}

According to the U.S. Environmental Protection Agency, Americans spend, on average, 90 percent of their time indoors. A non-smoking pathway in the ARIA Resort and Casino allows guests to walk from the registration lobby to the elevator bank with no exposure to tobacco smoke. This pathway is clearly marked, and non-smoking slot machines and gaming tables on each side of the pathway create a 20 -foot buffer. Similar measures are put into practice every day to maintain the enhanced air quality and overall comfort of CityCenter. To ensure a healthier environment and maximize the well-being of CityCenter residents and visitors, a stringent indoor air quality plan was implemented during construction [4].

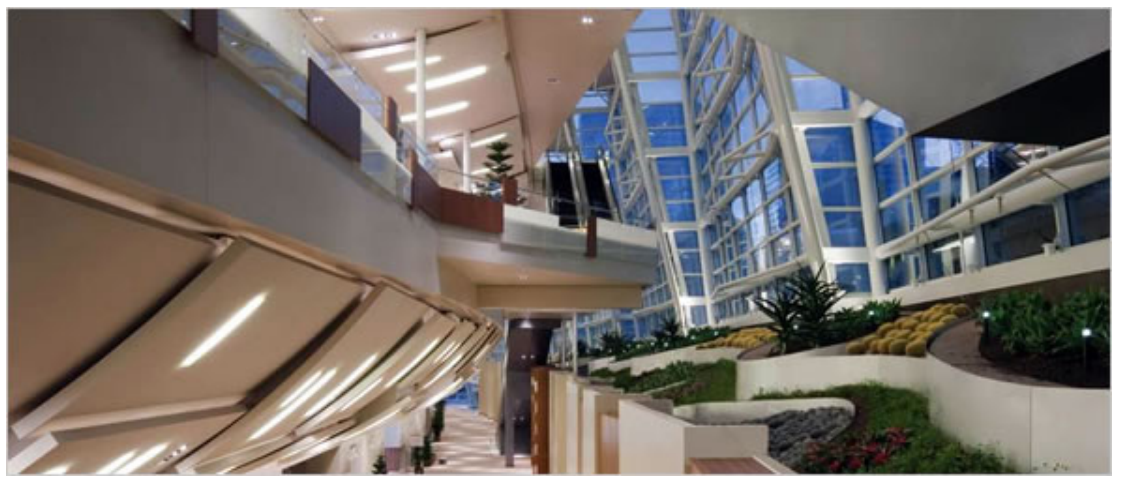

Figure 4: $\quad$ Aria Hotel and Casino. 
During construction of CityCenter, developers selected paints, sealants, adhesives, carpet and composite wood products that do not contain toxic substances that can later be released into the environment. Touch-ups and renovations contain similar non-toxic products.

During the construction of CityCenter, workers were limited to designated smoking areas, thus eliminating the potential for wallpaper and carpet to absorb tobacco smoke and protecting the air quality in guest rooms. In addition, all hotel rooms and residences were carefully sealed to prevent migration of tobacco smoke between units.

Traditional casino airflow is directed from the ceiling downward to the floor, pushing the air around guests. The airflow in ARIA's casino moves air from the floor to the ceiling, resulting in an odor-free, more comfortable environment. CityCenter properties only use cleaning products that meet strict health and environmental standards.

\section{Recycling}

Construction activities generate great quantities of solid waste that is typically disposed of in landfills. Disposing of construction debris into landfills not only wastes reusable resources, but also harms the environment by contaminating groundwater and emitting methane gas. Therefore, CityCenter has established, and continues to have, a comprehensive recycling program [5] as part of its effort to reduce waste products migration into the system.

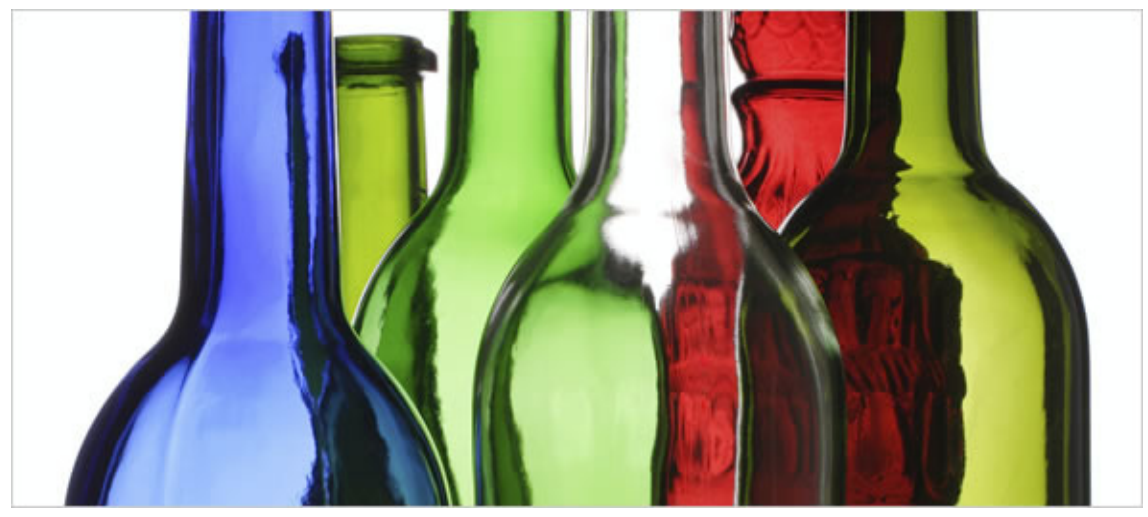

Figure 5: Recycled bottles.

Committed to reducing its environmental footprint, the CityCenter developed a strict construction waste management plan at the outset of the project to redirect recyclable and reusable resources back into the manufacturing process. CityCenter sits on the site of the old Boardwalk hotel. Before construction began, a single structure had to be removed. More than 90 percent of the materials were reused or recycled, keeping tons of materials from going into 
local landfills and preventing the need to manufacture new materials where old materials already on site could be utilized.

Every opportunity to reuse the debris from the Boardwalk Hotel and Casino demolition was evaluated. Doors, hardware, scrap steel, other metals and carpet were sold to resellers; broken tiles, concrete and asphalt were taken offsite, crushed and used as structural filler; salvaged toilets and countertops were used in projects in Mexico. Waste streams were not only diverted from landfills, but it also significantly lessened the demand for virgin materials, new product manufacturing, and transportation.

CityCenter uses four recycling docks to separate and collect recyclable materials, such as paper, cardboard, plastic, glass, metals, kitchen grease and other commodities.

\section{Materials}

Construction activities generate great quantities of solid waste [6] that is typically disposed of in landfills. Disposing of construction debris into landfills not only wastes reusable resources, but also harms the environment by contaminating groundwater and emitting methane gas. Therefore, CityCenter has established, and continues to have, a comprehensive recycling program as part of its effort to reduce waste products migration into the system.

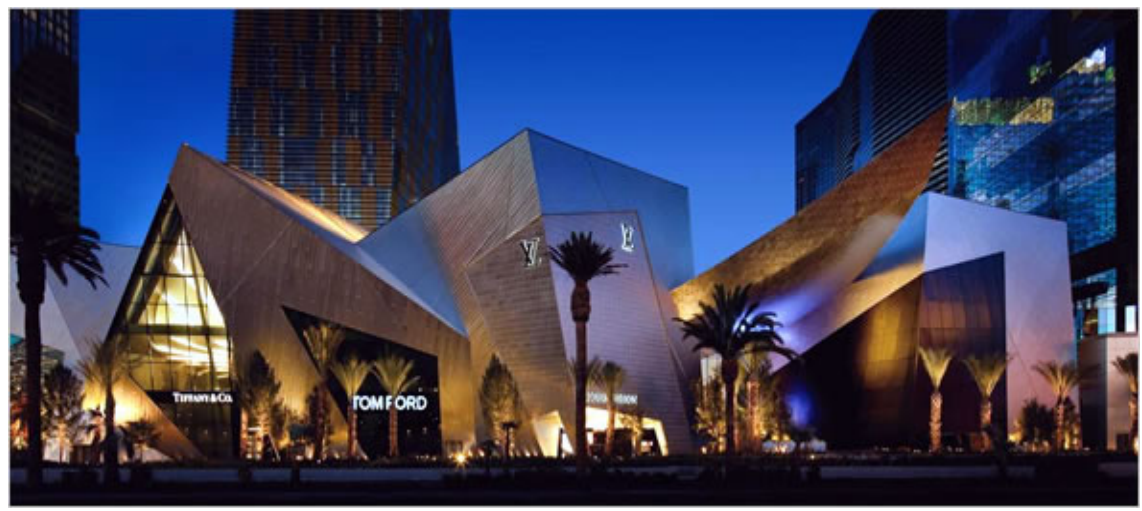

Figure 6: Crystals.

Committed to reducing its environmental footprint, the CityCenter developed a strict construction waste management plan at the outset of the project to redirect recyclable and reusable resources back into the manufacturing process. CityCenter sits on the site of the old Boardwalk hotel. Before construction began, a single structure had to be removed. More than 90 percent of the materials were reused or recycled, keeping tons of materials from going into local landfills and preventing the need to manufacture new materials where old materials already on site could be utilized. 
Every opportunity to reuse the debris from the Boardwalk Hotel and Casino demolition was evaluated. Doors, hardware, scrap steel, other metals and carpet were sold to resellers; broken tiles, concrete and asphalt were taken offsite, crushed and used as structural filler; salvaged toilets and countertops were used in projects in Mexico. Waste streams were not only diverted from landfills, but it also significantly lessened the demand for virgin materials, new product manufacturing, and transportation.

CityCenter uses four recycling docks to separate and collect recyclable materials, such as paper, cardboard, plastic, glass, metals, kitchen grease and other commodities.

\section{Transportation}

CityCenter is a multi-use urban resort destination, complete with hotels, residences, restaurants, shopping, and entertainment all within walking distance. Additionally, easy access to public transportation [7], including buses and the monorail, within a quarter-mile of CityCenter helps to reduce dependence on personal vehicles.

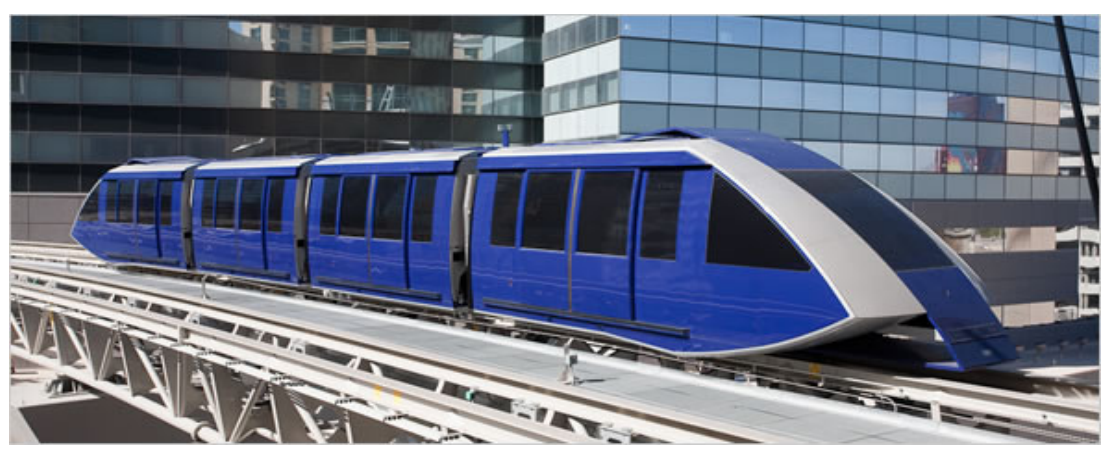

Figure 7: Monorail at CityCenter.

Guests who bike to CityCenter have access to valet services, while residents can utilize a bicycle storage area in their building.

Employees, residents, and guests who drive hybrid and electric cars have access to preferred parking to encourage the use of alternative-fuel or low-emission vehicles.

Employees and residents who carpool, bike, walk, or take advantage of other alternate modes of transportation can earn rewards through Club Ride, a program offered by the Regional Transportation Commission (RTC) of Southern Nevada to reduce traffic congestion and improve air quality.

\section{Transformation}

Early in the design process, the CityCenter team educated interior designers about the project's LEED goals. Later, construction professionals and trades were 
educated in green building techniques. Retailers at Crystals were encouraged to follow suit and use sustainable design and consider LEED certification in their leased spaces.

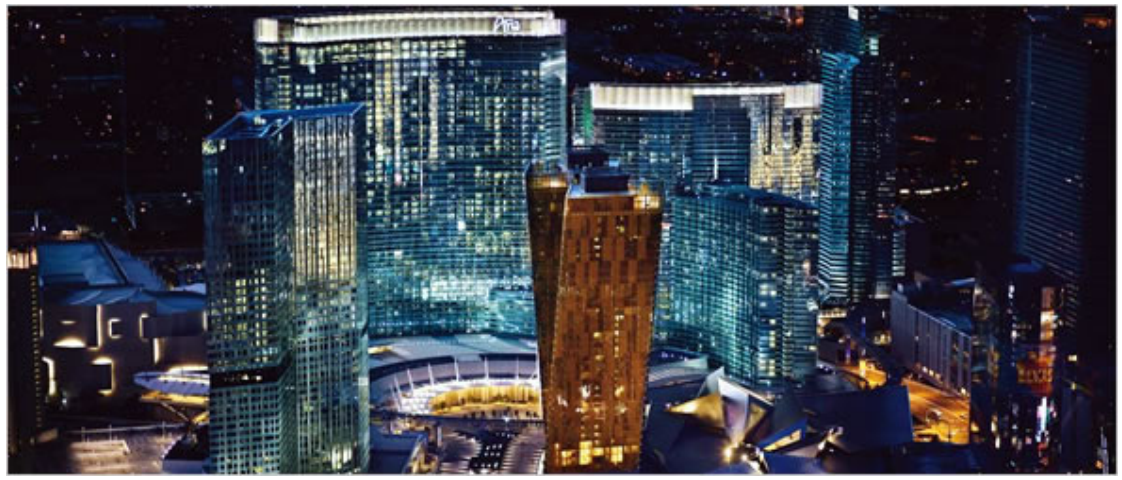

Figure 8: CityCenter at night.

When construction gave way to operations, every effort was made to continue to educate each of the 12,000 new employees as well as the residents and guests about the environmentally sustainable features. Day-to-day operations continue to be driven by dedication to sustainable practices.

A local Las Vegas recycling company, partnered with the CityCenter to establish a viable construction and demolition waste recycling market in Las Vegas. When the project began, no local recyclers could support an 18 million square foot construction project. CityCenter supported the construction of a new recycling facility to handle the volume of waste. As a result, more than 94 percent of CityCenter's construction waste was diverted from landfills.

Manufacturers of faucets, showerheads, and toilets worked with the CityCenter team to develop products that are environment-friendly and aesthetically pleasing. This effort not only saves nearly 50 million gallons of water at CityCenter annually. This second order of magnitude effect led to making it easier and more desirable to purchase environmentally sustainable products and services by the general public [8].

\section{Conclusion}

Continuous education is an integral part of CityCenter's commitment to sustainability. These efforts not only benefited CityCenter, but the more than 7,000 vendors, retailers, construction workers, and interior designers who can contribute their new-found sustainability knowledge and experience to future projects, extending CityCenter's commitment to the environment far beyond Las Vegas. 


\section{References}

[1] MGM Resorts International. CityCenter Web Site, Las Vegas, NV www2.CityCenter.com/environment/commitment/

[2] MGM Resorts International. CityCenter Web Site, Las Vegas, NV www2.CityCenter.com/environment/energy/

[3] MGM Resorts International. CityCenter Web Site, Las Vegas, NV www2.CityCenter.com/environment/water/

[4] MGM Resorts International. CityCenter Web Site, Las Vegas, NV www2.CityCenter.com/environment/wellness/

[5] MGM Resorts International. CityCenter Web Site, Las Vegas, NV www2.CityCenter.com/environment/recycling/

[6] MGM Resorts International. CityCenter Web Site, Las Vegas, NV www2.CityCenter.com/environment/materials/

[7] MGM Resorts International. CityCenter Web Site, Las Vegas, NV www2.CityCenter.com/environment/transportation/

[8] MGM Resorts International. CityCenter Web Site, Las Vegas, NV www2.CityCenter.com/environment/transformation/ 